\title{
11 SCARCITY AND CORRUPTION IN AfRICA: A MORAL-PHILOSOPHICAL APPROACH
}

\section{Theodros Teklu ${ }^{1}$}

\section{INTRODUCTION}

In recent decades, scholars have considered ubuntu - that a person is a person through other persons - as a defining feature of African socio-ethical life. This suggests that traditional ways of living together do still have a bearing on African societies. On the other hand, the African social philosopher, Achille Mbembe, argues that the practices of the self that institute identity are not commensurate with discourses on Africa that accentuate traditional modes of being. ${ }^{2}$ Put differently, what determines the self-formation of people in Africa are not necessarily traditional ways of living, but global processes that influence their subjectivities. One such experience which decisively contributes to the formation of subjectivity is scarcity and the concomitant culture of corruption, which is a social "behavior of public officials which deviates from accepted norms in order to serve private ends". ${ }^{3}$

Indeed, economic scarcity and a culture of corruption intimately condition our human coexistence and flourishing. By human flourishing I mean "a kind of living that is active, inclusive of all that has intrinsic value, and complete, meaning lacking in nothing that would make it richer or better". ${ }^{4}$ In other words, scarcity caused by immoral practices, such as corruption, negatively affects human flourishing. Whether as a descriptive fact that there are finite resources in the world, or as a normative concept, as a precondition for economic exchange, be it actual or perceived, economic scarcity seems to be inevitably and intricately linked to our human condition. Of course, our understanding of scarcity cannot be divorced from how we conceive, imagine or construe ourselves. For this reason, it would not be inappropriate to describe scarcity as an imagination that constitutes our modern subjectivity. In which case, scarcity is not only about fact, but also value or morality, requiring moral-philosophical reflection.

1 Research Fellow, Department of Systematic Theology and Ecclesiology, Stellenbosch University, and Lecturer in Philosophical Theology and Ethics, Ethiopian Graduate School of Theology.

2 Mbembe A. 2002. "African Modes of Self-Writing", Public Culture 14(1):239-273.

3 Huntington S. 1968. Political Order in Changing Societies. New Haven: Yale University Press, 59.

4 Nussbaum M. 2005. "Mill between Aristotle and Bentham”, in Bruni L and Porta PL (eds). Economics and Happiness: Framings of Analysis. Oxford: Oxford University Press, 171. 
This chapter aims to inquire as to what it might mean to speak of scarcity as a regime of subjectivity and to consider the scope available to express this within the discourse of corruption and human flourishing in Africa. To this end, I will organise my study in two stages. Drawing on the thought of French philosopher Jean-Paul Sartre, I will first discuss scarcity as a regime of subjectivity shaping people's imagination and action. This discussion will be enriched by the work of Mbembe who argues that the relation of human subjects to material resources and manufactured goods, which are considered scarce, constitute the practices that shape individual selves in contemporary Africa. Second, I will briefly look at African realities characterised by corruption, to explicate how scarcity is implicated in practices of corruption and how the phenomenology of religious experiences sheds light on our understanding of corruption in Africa. I will attempt to draw some implications for the legal consciousness and religious sensibilities of Africans before offering a brief conclusion.

\section{SCARCITY AS A REGIME OF SUBJECTIVITY}

The governing question in this section is "What might it mean to speak of scarcity as a regime of subjectivity?" I intend to address this question in dialogue with the works of Jean-Paul Sartre and Achille Mbembe. Given the limited scope of this chapter, I will focus my discussion to the subjective aspects of scarcity and its influence on human relations as a preliminary step towards initiating discussion focusing on corrupt and unethical relations sanctioned by culture.

\section{Conceptualising scarcity}

In the introduction, I defined scarcity, tentatively, as a fact or belief that there is not enough for everyone. Let me now resort to Sartre, who offers a more comprehensive definition: scarcity refers to an actual or perceived insufficiency of "a particular natural substance or manufactured product in a particular social field, given the number of members of the groups or [the] inhabitants of the region. There is not enough for everybody." 5 For Sartre, the discrepancy between the requirements of individuals and the supply of goods, presupposed by scarcity, is, mostly, a social construct. Often, Sartre distinguishes "sustained scarcity", which is created by human praxis and is the focus of this chapter, from a natural static form of scarcity. ${ }^{6}$ Natural scarcity implies the actual shortage of natural resources, while sustained scarcity entails the role of human agency. Unjust economic relations, which foster unhealthy competition, replicate or sustain scarcity. Even in resource rich countries, many suffer from scarcity due to lack of fair economic distribution. 
Cognisant of the close link between scarcity and human praxis, Sartre claims that "the whole of human development, at least up to now, has been a bitter struggle

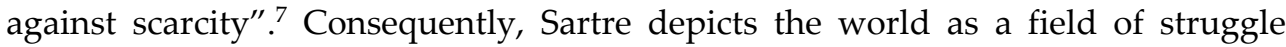
where the fittest survive, affecting not only human-human relations, but also human-environment relations. Here, the picture is that of a social struggle for survival akin to social Darwinism or Malthusianism.

Allow me to elaborate the nature of this struggle by looking at Sartre's understanding of human reciprocity: "In pure reciprocity, that which is Other than me is also the same. But in reciprocity as modified by scarcity, the same appears to us as anti-human in so far as this same man [sic] appears as radically Other - that is to say, as threatening us with death." ${ }^{8}$ Here, Sartre contrasts between "a positively idyllic human condition where human benevolent reciprocity governs) and a milieu of scarcity (in which life is characterised by a negative competitiveness that affirms social-Darwinian survival of the fittest)". ${ }^{9}$ By milieu, I here mean a social matrix into which we are born and which conditions the way we see the world.

In a milieu of scarcity, I see the other as a threat to my own existence, because I tend to prioritise the existence of my own self over that of the other. Put differently, scarcity affects and negatively transforms our human relationships, undermining the communal collaborative ethos of society such as ubuntu. Therefore, scarcity reveals not only the humanity and sameness, but also the anti-humanity, of the Other. In a similar vein, Mbembe expounds the phenomenon of scarcity, relating it to an economy of desire, which he considers to be a "transformative force" 10 in Africa. As we will examine below, echoing Michel Foucault's "practices of the self", ${ }^{11}$ scarcity, is transformative because it informs the way we imagine and act, which is inseparable from the practices of everyday life that shape our self.

\section{Scarcity and African practices of the self}

Mbembe addresses the question of scarcity within the wider framework of his discussion of postcolonial African identity. In his article, "African Modes of SelfWriting", Mbembe evaluates two modes of thought or "self-writing"12 that have emerged in Africa to make sense of Africanity prior to his discussion of scarcity.

7 Sartre, Critique of Dialectical Reason, 123.

8 Sartre, Critique of Dialectical Reason, xviii-xix, 131-132.

9 Teklu TA. 2018. “Economic Scarcity, Divine Fecundity: Moral Considerations”, Philotheos 18(1):161-174.

10 Mbembe, "African Modes of Self-Writing", 271.

11 Foucault M. 1994. "On the Government of the Living”, in Rabinow P (ed). The Essential Works of Foucault 1954-1984, vol. 1. London: Penguin Books, 81.

12 In the footsteps of Foucault who draws attention to the practices of the self that place considerable emphasis on writing, arguing that writing is one of the techniques by which the self is connected to the field of action, Mbembe highlights the role played by writing to explain the ways of being African (Africanity); cf. Mbembe. "African Modes of Self- 
The first mode of thought Mbembe engages with is the so-called instrumentalist paradigm, or "Afro-radicalism", which led to a synthesis of Marxist progressive politics with the ideology of nationalism. ${ }^{13}$ The second mode of thought, which Mbembe subjects to critique, is the "prose of nativism" (the "native condition" of Africa) or the traditional paradigm, which tries to make sense of African traditionality as distinct from its European counterpart. ${ }^{14}$ Instead of focusing on "the metaphysics of difference" - the difference between Africa and the West emphasised by the prose of nativism - Mbembe proposes exploring frontiers of human commonality in terms of the need to survive and flourish. ${ }^{15}$

The second mode of thought, which I will primarily be egaging with here, accentuates the native condition of Africa. According to this perspective, the African self - due to slavery, colonisation, and apartheid - has lost its connection with its authentic sources of the self. Consequently, there is a self-division or split of identity indicating the erosion of its authenticity. The remedy comes from the pursuit of establishing African uniqueness, African scholars highlight the importance of recovering their true tradition and customs, their philosophy and worldviews. This is why recovering authentic African practices of the self appears to be desirable.

The current emphasis on the significance of $u b u n t u$ by scholarly voices can be seen as part of the development referred to here as the trope of nativism. If one takes heed to the ongoing debate on the moral significance of $u b u n t u$, there is something of a propensity to make sense of this cultural experience by articulating it as a moralphilosophical expression towards developing an African moral theory. ${ }^{16}$ I agree with those moral philosophers who think that the task of the moral philosopher is not constructing an abstract ahistorical moral theory, but rather taking culturally and traditionally evolved norms and rules of a society and transforming them into moral conceptualisation. In this respect, the intellectual investment in the notion of ubuntu appears to be a viable one. Although such voices seek to reconstruct normativity from Africa's precolonial past, the contemporary realities that actually define African life appear to be different. Amongst the experiences that decisively contribute to the formation of people's subjectivities are the culture of corruption and scarcity, as reflected in the fact or belief that there is not enough for everyone.

According to Mbembe's argument, the two modes of thought briefly mentioned above are already exhausted, because what really constitute African identity today is different. Mbembe opens his article with an epigraph from Gilles Deleuze's

Writing", 239-273; Foucault M. 1994. "On the Government of the Living”, in Rabinow, The Essential Works of Foucault 1954-1984, 208.

13 Mbembe, "African Modes of Self-Writing", 240.

14 Mbembe, "African Modes of Self-Writing", 252-256.

15 Mbembe, "African Modes of Self-Writing", 240-241.

16 More MP. 2004. "Philosophy in South Africa Under and After Apartheid", in Wiredu K (ed). A Companion to African Philosophy. Malden, MA: Blackwell Publishing, 149-160; Metz T. 2007. "Toward an African Moral Theory", The Journal of Political Philosophy 15:321-341. 
Cinéma 2: L'image-temps, "The only subjectivity is time", 17 which implies that time constitutes human subjectivity. Put differently, human subjectivity is (re-)created temporally, drawing attention to the weight of the present. In this light, Mbembe offers a sample of three practices of the self that institute identity in contemporary Africa: (1) the state of religion; (2) practices of war; and (3) scarcity, which is the focus of this chapter.

For Mbembe, the phenomenon of scarcity relates to the economy of desire, which he considers a transformative force in Africa. As the definition of scarcity by economists show, there is a logical connection between scarcity and human behaviour at the centre of which is desire. Of course, as we have seen in Sartre's phenomenological analysis, we humans are imitative animals desiring what our fellow human being desires. Accordingly, the other is conceived as the same - like me, with basic needs for survival because he or she desires what I desire. However, because of the power of "mimetic desire" or mimetic rivalry, to echo the philosopher and anthropologist René Girard in a different context, the other is seen as a threat to my own existence or flourishing.

Consequently, the other is seen both as a human and as an anti-human and treated accordingly. This leads us to argue that scarcity implies violence - but of the silent sort, which is oftentimes taken for granted in everyday life ("violence as usual" or the "violence of things"). ${ }^{18}$ In other words, a spectacular violence or killing may not be carried out, but by depriving or withholding the goods essential for survival from them, society unwittingly exercises violence on the poor. This has important implications for corruption that benefits a few and impoverishes others.

Speaking specifically about the African context, Mbembe conceives scarcity as inseparable from unhealthy competitiveness. This is evidenced in the ways in which people react to shortages and scarcity that could be actual or imagined. Mbembe argues that all kinds of egoistic immoral attitudes emerge when people do not have easy access to consumable goods. Although consumption is a global phenomenon, the imaginary of consumption in Africa has certain distinctive features. Furthermore, Mbembe draws attention to the particular African "social imaginary" in the words of philosopher Charles Taylor, which emerges within the context of economic scarcity. By social imaginary, Taylor refers to "the ways in which [people] imagine their social existence ... the way ordinary people 'imagine' their social surroundings ... that common understanding which makes possible common practices."19 The social imaginary is about the self-understanding of

17 Mbembe, "African Modes of Self-Writing", 239.

18 "Thus, in imagination, individuals seem freer under the dominance of the bourgeoisie than before, because their conditions of life seem accidental; in reality, of course, they are less free, because they are more subjected to the violence of things"; Marx K and Engels F. 1999. The German Ideology. Arthur CJ (ed). New York, International Publishers, 84.

19 Taylor C. 2004. Modern social imaginaries. Durham: Duke University Press, 16. 
the subject within a social milieu that makes certain beliefs believable and certain practices normative. ${ }^{20}$

In a context, where access to material goods is difficult, desire appears to have a fictive nature, and consumption becomes phantasmic. This does not imply that material goods do not exist or that virtual reality replaces concrete existence. Instead, it implies a gap between the actual consumption of material goods and the desire for those goods. This gap invites regimes of subjectivity, which manifest in different ways. For example, short-term calculations and various strategies of extraversion emanate from this gap where scarcity - as a regime of subjectivity - operates.

Such conception helps us to understand the relation of the African subject to scarcity and corruption. To speak of scarcity as a regime of subjectivity means to speak of all kinds of unethical exchanges, which qualify as corruption, implying that scarcity is constitutive of the making or cultivation of the self. In other words, the imagination of scarcity shapes our economic behaviour, and whether we act ethically or not is determined by the way we conceive reality. Therefore, scarcity as a regime of subjectivity implies the transformation of ourselves, and our social relationships. In what follows, I will briefly explain how scarcity is implicated in practices of corruption and how the phenomenology of religious experience serves as a heuristic lens to understand the culture of corruption in Africa.

\section{CULTURE AND/OF CORRUPTION IN AFRICA}

The foregoing discussion furnished us with the phenomenology of scarcity, and how it shapes us as a regime of subjectivity. Here, I would like to argue that corruption is deeply implicated in an economy characterised by sustained scarcity. As a cultural phenomenon, corruption defines Africa, and the phenomenology of religious experience further consolidates that.

\section{Corruption as a cultural phenomenon}

Contradictory facets of development are taking place in Africa today. On the one hand, Africa is aspiring to grow economically. On the other hand, all kinds of unethical, corrupt exchanges are on the rise. Empirical studies confirm that Africa is

20 In The Imaginary Institution of Society, Castoriadis articulates the subject's selfunderstanding of himself/herself participates in significations that surpasses him or her. See Castoriadis C. 1998. The Imaginary Institution of Society. Cambridge, MA: MIT Press. Ricoeur claims that "[w]ithout imagination, there is no action", Ricoeur P. 1991. "Imagination in Discourse and Action", Blamey K (transl.), in Blamey $\mathrm{K}$ and Thompson JT eds). From Text to Action. Evanston: Northwestern University Press, 168-187. In his discussion, Mbembe is not clear whose understanding of the social imaginary he makes reference to; cf. also Ward G. 2005. Cultural Transformation and Religious Practice. Cambridge: Cambridge University Press. 
a continent where corruption is rampant. Both systemic and individual corruption at grand and petty levels are evident. In consequence, the African Union has decided to make 2018 to be the inaugural anti-corruption year, demonstrating how corruption has become a serious problem for the continent. Of particular interest, here, is the manner in which the cultural legitimisation of corruption - through sayings and stories - reverberates, and I will focus on a few examples that are illustrative of the connection between imagined scarcity and the culture of corruption.

The most common saying in Amharic (Ethiopia's official language), is "Sishom yalbela sishar yikochewal", a literal translation of which is "he who does not take advantage of his position [literally eat], will regret it when he is deposed".${ }^{21}$ Clearly, this saying encourages the public servant to misuse his or her service for personal gain. Moreover, scarcity is implied or assumed, in that it conveys the message that public positions are scarce. Generally, the saying suggests an attitude, shared by those who assume public offices and the general public, which normalises corrupt or unethical exchanges.

There are also other sayings that seem to encourage people to accept corruption as normal. Nowadays, it is quite common to hear people saying "zega", "amelete", "sera", which all convey a meaning similar to English colloquialisms such as "closing a deal", "hitting a home run" or "taking off", and "making it", respectively. ${ }^{22}$ In the contemporary Ethiopian context, these expressions are almost uniquely used to describe financial gain through corruption, with no implied critique of such means. Such colloquialisms thus serve to indicate how culture could legitimise corruption of bureaucratic officials.

However, such sayings should not give the wrong impression that corruption is always legitimised by society. In fact, there are sayings that critique corruption: "abatu dagna liju kemagna" meaning "the child is the robber, the father is the judge". ${ }^{23}$ This saying illustrates the picture of a corrupt child who does not get punished because of his relational advantage that helps him to escape the criminalisation of his corrupt act. We can, therefore, conclude that in general, we can discover both the legitimation and critique of corruption in Ethiopian society.

To make proper sense of these sayings requires that we take into account the social context where there is sustained scarcity and a concomitant struggle for survival and flourishing. If it were not for the limited scope of this chapter, countless poetic expressions from across Africa could be cited. Nonetheless, it suffices to draw attention to the few discussed in this section to conclude that culture plays

21 Mekonnen SS. 2014. Thumbs Up or Down to Corruption? A Study of Inhabitants in Addis Ababa, MA Thesis, Addis Ababa University, College of Social Sciences, Department of Social Anthropology, 2.

22 Mekonnen, Thumbs Up or Down to Corruption?, 2.

23 Mekonnen, Thumbs Up or Down to Corruption?, 2-3. 
a significant role in legitimising and countering corruption. Let me conclude with the poem "Udoji" by the Nigerian poet Osundare, which exposes the seriousness of bribery and corruption in Nigeria and its consequent inflation affecting human flourishing:

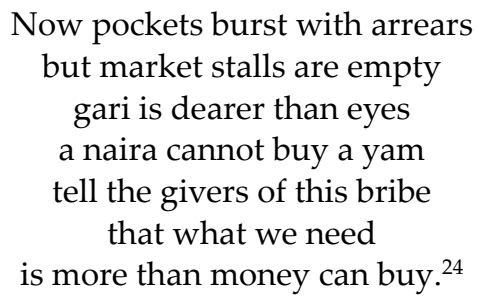

\section{The state of religion}

Such poetic expressions raise several questions regarding corruption and the culture that sanctions it. For example, one wonders how corrupt practices flourish in societies that are deeply religious. Even though offering a substantial analysis of religious beliefs and groups is beyond the scope of this chapter, I will make a cursory rehearsal of Mbembe's analysis of "the state of religion" 25 in Africa, focusing on the rise of neo-Pentecostal or charismatic forms of Christianity in order to argue that the state of religion could be taken as a paradigmatic example of what takes place within the cultural matrix of Africa. Central to Mbembe's analysis is the domain of the miraculous or the supernatural in which "the belief that anything is possible" saturates the imagination of the adherents. ${ }^{26}$ This has clear connections with the believer's relations with the material world ("earthly polis") and the spiritual one (the heavenly Kingdom of God) - a division that does not clearly delineate between the world and the beyond (a characteristic feature of otherworldliness).

For African Christians, "the flow of wealth/money/statuses do not belong to the domain of the natural only". ${ }^{27}$ The hierarchic categorical distinction between the earthly and the heavenly has direct implications for the religious believer seeking to influence his or her material life when constrained or determined by scarcity. What enables one to go beyond the limits of material life is the power of the miraculous or the supernatural. Unleashing or releasing the supernatural is dependent on how one relates to charisma, which demonstrates a paradox. Charisma is for and accessible to everyone, and thus abundant, while it is practically possessed only by a few, and thus scarce. Individual believers who are desperate in overcoming scarce material conditions, such as unemployment and poor living conditions, seek to change their

24 Odinye IE. 2014. "The Image of Corruption and Poverty in Contemporary Nigeria: A Study of Osundare's Songs of the Marketplace", AJELLS 5(1):12-22.

Mbembe, "African Modes of Self-Writing", 269-270. Mbembe, "African Modes of Self-Writing", 270.

Teklu TA. 2018. "Meritocracy and inequality: moral considerations", Palgrave Communications 4(4):6. 
"fate" by deploying charisma ... either their own or through the ministry of other gifted, or "anointed" ones. A caveat here: such an interpretation of charisma should not give the impression that altruistic motives are totally or entirely displaced by instrumental reasoning.

The operation of charisma in religious circles raises serious questions as to whether it is totally free from the transactional economic logic. If charisma is not free from the economic logic of exchange, then it would be appropriate to stick monetary tags to religious practices, such as prayer. This would eventually lead to the commercialisation or "commodification of religion" 28 itself. The challenge in Africa is precisely this gradual degradation of moral values insinuating itself within religious contexts.

Mbembe discusses the state of religion without any reference, or evaluation of, charisma vis-à-vis economy. Of course, Mbembe does not conjoin the two - his analysis of the state of religion and his discussion of scarcity. He deals with them as if they are separate practices of the self shaping Africans. In this chapter, I suggest that conjoining these two could be conceptually profitable to understand the situation in Africa. A necessary caveat here is that I am not arguing there is a direct connection between certain forms of Christianity mentioned above and the practices of corruption. Instead, I suggest that understanding the phenomenology of religion as a cultural practice could be hermeneutically illuminating to understand how people imagine and live-out their world. ${ }^{29}$

In general, the phenomenon of religion in Africa illustrates how cultural practices could easily sanction unethical exchanges. This suggests that underlying corrupt practices are the imagination of scarcity infiltrating even the religious domain. Countering such tendencies requires not only the implementation of law, but demands engagement at a deeper religious and cultural level. In what follows, I will look at the implications for human flourishing, focusing on law and religion.

\section{IMPLICATIONS FOR HUMAN FLOURISHING}

Having thus far looked at why and how corruption should be conceived from the perspective of scarcity we now ask what scope is available to discuss this within the discourse of corruption and human flourishing? To address this question, we need to look at how the legal and religious spheres relate to scarcity and corruption. In what follows, I will briefly draw some implications the problem of scarcity and associated practices of corruption pertinent to law and religion.

28 Ward G. 2005. "The Commodification of Religion, or The Consummation of Capitalism", in Davis C, Milbank J and Zizek S (eds). Theology and the Political: The New Debate. Durham: Duke University Press, 327-339.

29 Here, I am not reducing religion to culture, neglecting the transcendental reference in religion that makes it irreducible to culture. Instead, I am acknowledging the fact that culture proves to be religion's field of operation. 


\section{Legal implications}

The current global fight against corruption can be traced back to the establishment of International Transparency in 1993 by Peter Eigen, who served as the director for the regional mission of the World Bank in East Africa, and the 1996 declaration of then president of the World Bank, James Wolfensohn, that corruption was the main cause of poverty. ${ }^{30}$ Such a change of mood in the World Bank influenced African states and served to initiate the wide range of research on corruption which ensued.

To date, the legal approach has been the dominant intervention, and not adequately and successfully supplemented with other approaches. Of course, various systemic improvisations such as the setting up of anti-corruption commissions for greater surveillance and control, and salary increases for public officers have been characteristic features of anti-corruption intervention. Some propose that anti-corruption strategies should be assisted by efficient information and communications technologies. ${ }^{31}$ By and large, studies on corruption and anti-corruption strategies still appear to focus on objective structures such as institutions, both governmental and non-governmental, and the nature of corruption, whether grand or petty, systemic.

While it is appropriate to carry out research on institutions - since institutions constitute our modes of togetherness - overplaying this angle without, or at the expense of, the subjective dimension can be reductive in approach. My contention is that the legal approach and other strategies that focus on objective institutional structures tend to be reductive, since they focus on criminalisation of corruption. Arguably, the criminalisation of corruption alone would not be efficient in the combat against corruption. Sometimes, "in a society where corruption is widespread the passage of strict laws against corruption serves only to multiply the opportunities for corruption". ${ }^{32}$ Nonetheless, one may legitimately raise the question whether "more criminalization produces more punishments", a situation called "overcriminalization" by Douglas Husak, a prominent philosopher of criminal law. ${ }^{33}$ One way of avoiding the dangers of overcriminalisation, I propose, is dealing with corruption at the cultural level, including the domain of religion.

Having said this, however, I wish to distinguish my proposal from the realist school of thought that evokes the role of culture, albeit in a manner supportive of corruption. According to this school, which is articulated by the American

30 Galtung F. 2000. "A global network to curb corruption: the experience of Transparency International", in Florini A (ed). The Third Force: The Rise of Transnational Civil Society. Washington: Carnegie Endowment for International Peace, 17-48.

31 Shim DC and Eom TH. 2009. "Anticorruption effects of information communication and technology (ICT) and social capital", International Review of Administrative Sciences 75(1):99-116.

32 Huntington, Political Order in Changing Societies, 62.

33 Husak D. 2008. Overcriminalization: The Limits of the Criminal Law. Oxford: Oxford University Press, 93-103. 
political scientist Samuel Huntington, consider corruption as something that helps to expedite certain things. ${ }^{34}$ On this view, the clash between traditional values and the demands of modernisation or institutionalisation and is inevitable in the developmental stages of all states. ${ }^{35}$ What the legal approach calls corruption is referred to as "gift-exchange" by this school of thought. From this perspective, the legal positivist approach is both reductive and counter-productive in that it undermines cultural or contextual diversity and lacks the pragmatic aspects of social relations necessary for human flourishing. Against this reasoning, I contend that although modernisation may posit a challenge on tradition, society must properly uphold the cultural norms that do not sanction corruption, fostering legal consciousness. Thus, the legal approach must be effectively supplemented by cultural norms and practices that condemn the culture of corruption.

\section{Religious implications}

In the classical paradigm of criminal justice - the so-called natural law - we find the conjoining of the moral and the legal spheres. Despite the modern positivistic paradigm that bifurcates the two, morality and law can complement each other. According to natural law, corruption could be seen as both a moral wrong and a public wrong. In other words, corruption should be punishable not only because it violates the rules or legal codes of a consensus society or public, but also because it transgresses moral norms. The moral wrong could be regarded as a vice (patristic) and $\sin$ (medieval), which is meaningful in a given cultural context. This implies that corruption is not only a legal issue, but also a cultural and religious one.

Classical, patristic, and medieval philosophical and Christian theological writings reveal that corruption has connections to the cultivation of the self and the "care of the soul". ${ }^{36}$ Plato's Republic and other similar writings affirm the relationship between corruption and the government of oneself. ${ }^{37}$ For St. Augustine, as for St. Aquinas after him, corruption or corruptibility has to do with human privation caused by the original sin. The topic of desire - that desire's disorder could result in corruption - is an important contribution of St. Augustine.

Theologically, corruptibility - which is not yet corruption, but the potential for the crime of corruption - is part of the condition of humanity. Conjoining the notion of desire with corruption, theological thinkers furnish us with an arsenal of preventive anti-corruption strategies. Desire is not a bad thing as such, for it can also be positive. Desire does not necessarily imply lack; instead, it implies production. ${ }^{38}$

34 Huntington, Political Order in Changing Societies, 59-71.

35 Huntington, Political Order in Changing Societies, 59-61.

36 Foucault, "The Genealogy of Ethics", 284.

37 Martin LH, Gutman H and Hutton PH (eds). 1988. Technologies of the Self: A Seminar with Michel Foucault. London: Tavistock, 16-49.

38 Deleuze G with Guattari F. 1983. Anti-Oedipus: Capitalism and Schizophrenia. Hurley R, Seem M and Lane HR (transl.). Minneapolis: University of Minnesota Press, 186. 
Consequently, desire produces desire, implying that it is not only lack of desired goods, but also the production of more desire and the consumption of produced goods. The right ordering of desire, on the other hand, fosters human flourishing. A proper re-orientation of desire is the antidote to the egoistic desire of satisfying one's own needs and wants through corrupt practices.

Religion can effectively supplement the legal approach only in so far as it practically overcomes the desire for unethical, corrupt exchanges. As theologian Daniel Bell Jr argues, deploying theoretical resources of continental post-Marxist philosophers Gilles Deleuze and Michel Foucault, we are practically conditioned by "the banality of consumption" and "technologies" of desire, forcing us towards certain capitalistic goals. ${ }^{39}$ Humanity is continually pressured to participate in the "market processes" and, consequently, to be human means to participate in an economy of production and consumption. ${ }^{40}$ This is not to suggest that people would do well if they were to refrain from such actions that are vital for survival and flourishing. Instead, the suggestion is that we be cognisant of the fact that religion can be challenged by the commodification of values, including the commodification of religion itself.

The safeguarding of the moral sphere from the aggressive expansion of the economic sphere has drawn the attention of social philosophers such as Michael Walzer and Michael Sandel. For Walzer, there should always be "shared values" that are not subsumed in a market economy. ${ }^{41}$ What binds us together are these values, which, if subjected to the economic logic of exchange would be made vulnerable to contamination by corruption. What is ultimately at stake, here, is that the moral sphere may be commodified - that is, the moral values could be given a monetary value. This is a concern, because the economic sphere with its logic of exchange expands to the sphere of moral values, which are and should remain non-purchasable.

In fact, Walzer's and Sandel's presupposition that the two spheres - the sphere of morality and the sphere of economy - are distinct and autonomous orders could be problematic: "It is plausible that the logic of markets ought not to be extended to any and all realms of life. It is not plausible, however, that normative morality and economics follow two entirely different orders." ${ }^{\prime 2}$ This implies that the sphere of economy should not operate behind a moral veil. Morality should govern economic relations in order to avoid corruption and unethical exchanges and ultimately to overcome the challenge of late modern society that commercialises most aspects of life. This requires paying attention to social locations where non-purchasable shared

39 Bell DM. 2012. Series editor's Foreword to The Economy of Desire: Christianity and Capitalism in a Postmodern World by Smith KA. Grand Rapids, MI: Baker Academic, 9-11.

40 Bell, The Economy of Desire, 7.

41 Walzer M. 1983. Spheres of Justice: A Defense of Pluralism and Equality. New York: Basic Books, 97.

42 Rauen V. 2016. "Corruption: Uncovering the Price of Normative Morality and the Value of Ethics", Special Issue "Ethical Challenges of Corrupt Practices", German Law Journal 17(1):106. 
values are cultivated. In this respect, we could say that religious communities could positively contribute to anti-corruption remedies, provided that they practically overcome the commodification of values.

Finally, I wish to conclude by accentuating that theological resources, such as the ones hinted at above, could be generated in order to counter the disordering of desire. In his famous work The City of God, St. Augustine juxtaposes the city of God with the earthly city in order to suggest that the two are intermingled and as a consequence Christians must care for being-in-this world. ${ }^{43}$ This demands that they seriously consider not only their relationship to God but also their neigbour. The right ordering of desire or love, which is properly oriented towards their God and neighbour, serves as an antidote to the problem of desire, imagined scarcity and the commodification of values.

\section{CONCLUSION}

In this chapter, we have addressed the question: what might it mean to speak of scarcity as a regime of subjectivity and consider the scope available to express this within the discourse of corruption and human flourishing. First, I offered an interpretation of scarcity as a regime of subjectivity, generating insights from Sartre. Subsequently, such a discussion was further enriched by Mbembe's account of African practices of the self. Particularly, focusing on the poetic expression of Africa that sanction corruption, I have argued that corruption is a cultural phenomenon that affects even the domain of religion. Finally, we have looked at the scope available to express the interrelated aspects of scarcity and corruption within the discourse of human flourishing, focusing on the legal and religious implications. In terms of law, supplementing the legal approach with cultural assets such as ubuntu has been highlighted. With respect to religion, religion could be an arsenal against corruption insofar as it extricates itself from corrupting experiences that emanate from disordered desire. 